\title{
RESEARCH ON PARAMETERS INFLUENCING PERFORMANCE OF VIBRATING PLATFORMS DURING TRANSPORTING THE DRY EARTH MASS
}

\author{
Goran Mihajlović, Milomir Gašić, Mile Savković
}

Original scientific pape

One of the main requirements related to application of vibrating platforms is to achieve the maximum productivity during their operation and, at the same time, to break mass and separate some components from the mass itself. Application of response surface methodology (RSM), which is based on design of experiments $(\mathrm{DoE})$, resulted in mathematical model for exploring geometrical and kinematic parameters influencing the optimum operating performance of vibrating platform. The experiment was conducted by means of multifactor orthogonal plan type $2^{k}$ and hyperbolic curves were formed. It was also determined that these curves are always between the curves formed on the basis of results of theoretical model, which verifies the research results.

Keywords: dry earth mass; mathematical model; multifactor orthogonal plan of the experiment; operating parameters; transport; vibrating platform

\section{Istraživanje utjecajnih parametara na radni učinak vibracijskih platformi pri transportu suhe zemljišne mase}

Izvorni znanstveni članak Jedan od osnovnih zahtjeva pri korištenju vibracijskih transportnih platformi ogleda se u ostvarenju maksimalnog učinka tijekom njihovog rada, uz istovremeno usitnjavanje mase i odvajanje pojedinih sastojaka iz same mase. U radu je primjenom response surface methodology (RSM), koja je bazirana na design of experiments (DoE), formiran matematički model za istraživanje utjecajnih geometrijskih i kinematskih parametara na optimalni radni učinak vibracijske platforme. Provedenim eksperimentom, korištenjem višefaktornog ortogonalnog plana tipa $2^{k}$ formirane su krive hiperboličkog tipa i utvrđeno je da se one uvijek nalaze između krivih koje su formirane na temelju rezultata teorijskog modela, čime su potvrđeni i verificirani istraživački rezultati.

Ključne riječi: matematički model; radni parametri; suha zemljišna masa; transport; vibracijska platforma; višefaktorni ortogonalni plan eksperimenta

\section{Introduction}

In different areas of engineering such as: process industry, agricultural machinery, civil engineering, mining, etc., we are facing a variety of machinery, mechanical and technological systems that are used for transporting, separating and crushing the earthy solid mass. There are a lot of examples: in agriculture there are many machines which take out tuberous plants (potatoes, onions, beets, carrots) from the earth; in civil engineering there are special sieves through which the sand is sifted for the needs of both construction engineering and building construction; in mining various exploitation methods, which always include the processes of breaking and separating transported mass, are used depending on the physical and geological conditions of the site.

The principle of fragmentation is based on supplying the external energy needed to overcome the cohesion and adhesion forces which hold particles together. Only a few percents of supplied energy are used to overcome these forces, while the rest of the energy is lost, i.e. it is converted into heat (due to friction), acoustic energy (sound waves) and other dissipative forms of energy. The principle of separation is based on removal of some less important components (called "tailings"), while the material itself is enriched with more valuable ingredients in order to be efficiently used both in technical and economical terms.

The above mentioned processes are usually carried out on machines called crushers (for coarse and medium grinding) and mills (for fine grinding). However, the latest research shows that the processes of breaking and separating the solid mass can be carried out in a very rational and successful way by means of special vibrating platforms $[1 \div 4]$. The specific implementation of such technological systems, for example, in agriculture, is given in the paper [5]. The operation of these platforms is influenced by many different factors, and having in mind that this is a relatively new and unknown issue, it is necessary to conduct extensive theoretical and practical research in order to obtain relevant results necessary for a complete understanding of these processes. The aim is to use the obtained data and conclusions for the design, construction and exploitation of real mechanical and technological systems on which these vibrating platforms are built.

\section{Geometrical parameters affecting the work of vibrating transporting platforms}

Earthy solid mass is undermined by the plough and then piled onto the platform, or it is dumped from a funnel above the platform directly to the platform itself, which depends on the type and structure of a concrete platform machine. On the platform, the mass is broken due to dynamic impact and falls (i.e. sieves) through the grid built into the platform.

According to the number of grids there are mono-grid type and duo-grid type platforms [6]. Mono-grid vibrating platforms are widely used in practice (Fig. 1, case "a"). Their operation is characterized by the presence of high dynamic stresses caused by the action of inertial forces. Unlike them, duo-grid platforms operate with two grids simultaneously (Fig. 1, case "b"). Duo-grid platforms usually have higher performance (productivity) than mono-grid platforms and inertial forces on each grid are balanced because the accelerations on grids are always directed to the opposite directions. Therefore, whenever possible, preference should be given to duo-grid platforms, regardless of their more complex structure. Keeping in mind the whole technological process, it was 
concluded that duo-grid platform, whose excenter is as far from the bar as possible, is the most suitable in practice.

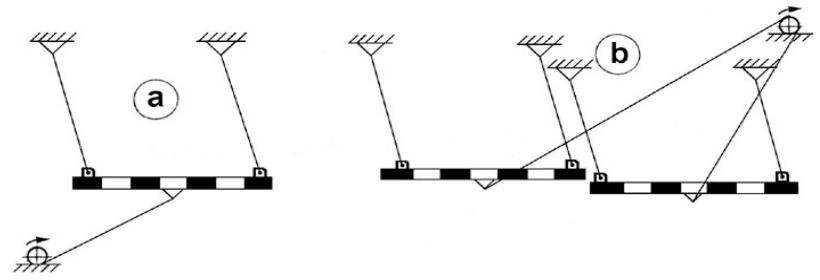

Figure 1 Types of vibrating platforms: a) mono-grid; b) duo-grid

According to [6] general scheme with the main parts and geometrical parameters which influence the working effect of vibrating transport platform is presented in Fig. 2.

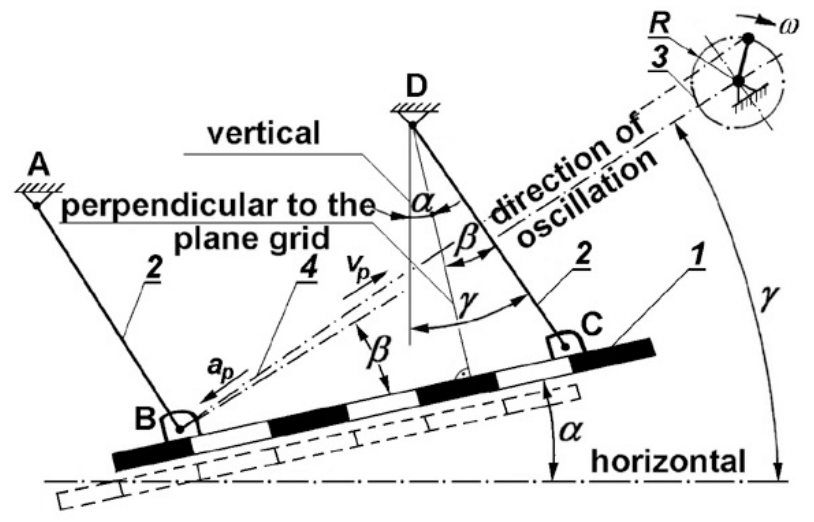

Figure 2 General scheme of vibrating platform (1 - platform; 2 suspension; 3 - excenter; 4 - driving lever; $A(R)$ - amplitude of oscillation of the platform (radius of the excenter); $\varphi$ - phase of platform oscillation; $\alpha, \beta, \gamma$ - influential angles of the platform; $\mathrm{A}, \mathrm{B}$, $\mathrm{C}, \mathrm{D}$ - supporting points of the platform)

\section{Kinematic parameters affecting the work of vibrating transporting platforms}

For the analysis of the parameters that affect the operation of vibrating platforms, first it is necessary to define all quantities which characterize the oscillatory movement of the platform [1]:

- frequency: $f=1 / T=n / 60 \mathrm{~Hz}$

$T$ - period of the platform oscillation $(s)$

$n$ - rpm of eccentric shaft of the platform $\left(\mathrm{min}^{-1}\right)$

- angular frequency: $\omega=2 \pi f=\frac{2 \pi}{T}=\frac{\pi n}{30}\left(\mathrm{~s}^{-1}\right)$

- amplitude $(A)$ which is equal to the radius of the eccentric shaft $(A=R)$ which drives actuator lever allowing platform oscillation

- both velocity of platform $\left(v_{\mathrm{p}}\right)$ and acceleration of platform $\left(a_{\mathrm{p}}\right)$ whose vectors are oriented in the direction of platform oscillation, which means that they are defined by the angle $\gamma=\alpha+\beta$ (Fig. 2).

In order to define the velocity $v_{\mathrm{p}}$ and acceleration $a_{\mathrm{p}}$ during oscillatory motion [1], the motion of material point $M$ can be observed along the circle of radius $R$ at constant angular velocity $\omega$ in the clockwise direction (Fig. 3).

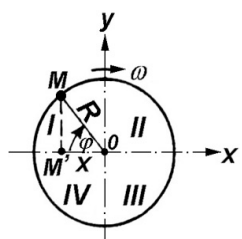

Figure 3 Kinematic characteristics of the oscillatory motion of platform (O - equilibrium position; $M^{\prime}$ - projection of point $M$ on the $x$-axis; $A \equiv R$ - amplitude of oscillation; $\varphi$ - phase of oscillation which determines the current state of oscillatory system $(\varphi=\omega t))$

It can be seen that the projection of point $M$ to the $x$ axis (that is point $M^{\prime}$ ) performs harmonic oscillations around the equilibrium position $\mathrm{O}$ (Fig. 3), and therefore elongation $\boldsymbol{x}$ can be presented as:

$x=-R \cdot \cos \varphi=-A \cdot \cos \omega t$

while the velocity $v_{\mathrm{p}}$ and acceleration $a_{\mathrm{p}}$ of the platform can be presented in the following way:

$v_{\mathrm{p}}=\frac{\mathrm{d} x}{\mathrm{~d} t}=\frac{\mathrm{d}}{\mathrm{d} t}(-A \cdot \cos \omega t)=\omega A \cdot \sin \omega t$

$a_{\mathrm{p}}=\frac{\mathrm{d} v_{\mathrm{p}}}{\mathrm{d} t}=\frac{\mathrm{d}}{\mathrm{d} t}(\omega A \cdot \sin \omega t)=\omega^{2} A \cdot \cos \omega t$

The velocity of movement during the oscillations, as can be seen from Eq. (4), is variable and has extreme values in the following cases:

a) $v_{\mathrm{p}}=v_{\mathrm{pmax}}$ for $\sin \omega t=1$

b) $v_{\mathrm{p}}=v_{\mathrm{pmin}}$ for $\sin \omega t=0$.

The acceleration, according to Eq. (5) also has extreme values in the following cases:

c) $a_{\mathrm{p}}=a_{\mathrm{pmax}}$ for $\cos \omega t=1$

d) $a_{\mathrm{p}}=a_{\mathrm{pmin}}$ for $\cos \omega t=0$.

During oscillatory motion acceleration $a_{\mathrm{p}}$ is always directed toward the equilibrium position, i.e. in the opposite direction of motion (opposite to the $x$ coordinate). As a result, there is an inertial force $F^{\text {in }}$ acting on the vibrating platform, which is directed opposite to the direction of platform acceleration $a_{\mathrm{p}}$ and which, therefore, needs to be properly balanced. The same inertial force is of a great importance for the platform operation. At a certain moment it acts on the particles of transported mass and forces them to slide "upwards" along the platform in the period during which the platform acceleration is directed "downwards". At a greater acceleration (during even harder dynamic modes of oscillation) it breaks the particles away from the platform grid and forces them to flow freely in the direction of transport of materials according to the laws of projectile motions. In this way, the transport of materials is significantly increased.

The variables $v_{\mathrm{p}}$ and $a_{\mathrm{p}}$ can be displayed graphically using a sine curve or a cosine curve. In a case where there is no inclination of the platform towards the horizontal line $(\alpha=0)$, in accordance with [6], it is possible to 
distinguish the following five basic operating modes of vibrating transport platform (Fig. 4):

1. low-speed mode without slipping material in the opposite direction (the case "a")

2. semihigh-speed mode with two pauses (the case "b")

3. semihigh-speed mode with one pause (the case "c")

4. high-speed mode without a pause (the case "d")

5. operating mode with rejection of material (the case "e").

During the low-speed mode (Fig. 4a) the speed of platform grid $v_{\mathrm{p}}$ and the speed of earth particle $u$ coincide with each other up to the point " $k$ " (the quadrant II) i.e. the particle travels together with the platform at the speed which is equal to the speed of platform $v_{\mathrm{p}}$, and then (in the point " $k$ ") negative acceleration of the platform grid $a_{\mathrm{p}}$ becomes so great that the force of inertia $F^{\text {in }}$ overcomes the friction force between the particle and platform $F_{\mu}$, and therefore the particle begins to slide upward the platform $\left(F^{\text {in }}>F_{\mu}\right)$. This slide takes place in the direction of transportation of the material, only once during a full rotation of the eccentric shaft. There is no slipping in the opposite direction. Transported amount of material $Q_{\mathrm{t} 1}$ during a full rotation of the eccentric shaft is shown graphically in the diagram with the shaded surface $P_{1}$. Thus, the following identical equality can be applied: $Q_{\mathrm{t} 1}$ $\equiv P_{1}$.

Increasing the frequency of oscillation leads to semihigh-speed mode with two pauses between the points: $m \div q$ and $n \div k^{\prime}$ (Fig. 4b). In this mode the particle slides upward (between the points $k \div m$ ) and downward (between the points $q \div n$ ). It means that the amount of material transported upward is defined by the surface $P_{2}$ in the diagram, while the amount of material transported downward is defined by the surface $P_{2}^{\prime}$, so the actual amount of material transported by platform is defined by the difference between surfaces $P_{2}$ and $P^{\prime}{ }_{2}$, i.e.: $Q_{\mathrm{t} 2} \equiv P_{2}-$ $P_{2}^{\prime}$.

If the frequency of oscillation continues to increase, platform moves on semihigh-speed mode with one pause between the points $n \div k^{\prime}$. In this case, the actual amount of material transported by platform is: $Q_{\mathrm{t} 3} \equiv P_{3}-P_{3}^{\prime}$ (Fig. 4c).

If the frequency of oscillation is further increased (Fig. 4d) platform moves on high-speed mode without a pause in materials transportation, i.e. in this case, the actual amount of transported material by platform is: $Q_{\mathrm{t} 4}$ $\equiv P_{4}-P_{4}^{\prime}$.

If we continue to increase the frequency of oscillation, platform moves on operating mode with rejection of material (Fig. 4e). In this mode, at the very beginning of the cycle (the point " $s$ " in the quadrant I) material slides downwards to the point " $d$ " (in the quadrant II) when the intensity of the acceleration of the particle is sufficient to reject it and then the particle is separated from surface of the platform and moves further as the body ejected at an angle $\gamma$ in relation to the horizontal (projectile motion). Then the transport of materials is the largest (surface $P_{5}$ on the diagram), while the transport in opposite direction (surface $P_{5}^{\prime}$ ) is relatively small, so the actual amount of material transported by platform is very large: $Q_{\mathrm{t} 5} \equiv P_{5}-P_{5}^{\prime}$.
Generally, for the amounts of transported material in any operating mode of platform, the following relation is valid: $Q_{\mathrm{t} 5}>Q_{\mathrm{t} 4}>Q_{\mathrm{t} 3}>Q_{\mathrm{t} 2}>Q_{\mathrm{t} 1}$.

With a further increase of amplitudes or frequencies of oscillation, it is theoretically possible to achieve such operating modes of platform in which the time of particle flight would be equal to the time which is required for one, two, three, ..., etc., rotations of the eccentric shaft. In this way it would be possible to break the solid mass completely, and a separating effect would be significantly increased. In such dynamic modes, operation of platforms must be based in real exploitation conditions.

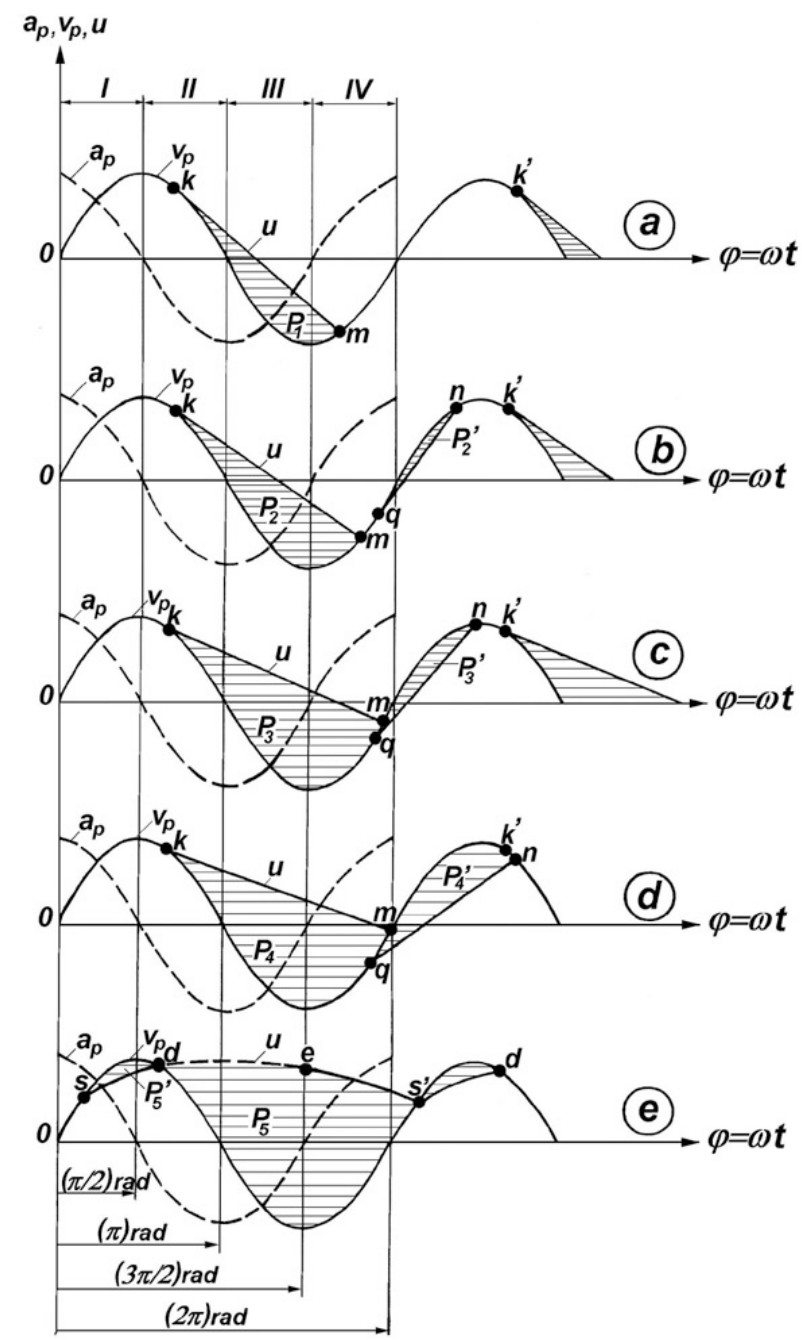

Figure 4 Modes of operation of vibrating transport platform ( $a_{\mathrm{p}}$ - platform acceleration; $v_{\mathrm{p}}$ - platform velocity; $u$ - acceleration of earth particles; I, II, III, IV - quadrants)

\section{Optimal working efficiency of vibrating transport platforms}

It is evident that the best working efficiency with regard to the transport of material is achieved in the operating mode with rejection of material, and for this reason only this case is considered in the paper. It is assumed that earth particles rejected from the platform move according to the laws of projectile motion [6]. The origin of coordinates (the point " 0 ") is the initial position $(t=0)$ of rejected earthy particle whose mass is $m$, axis $0_{y}$ is directed perpendicular to the plane of the platform, and 
axis $0_{x}$ is directed in the flight direction of the particle, i.e. in the direction of material transportation (Fig. 5).

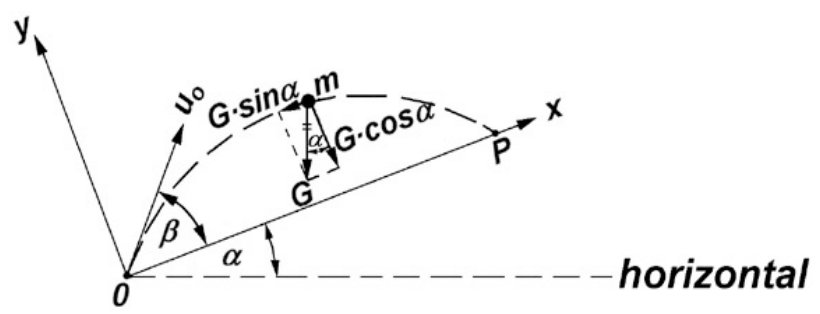

Figure 5 Earth particle rejected from the platform (projectile motion)

Movable earth particle whose mass is $m$ is situated in an arbitrary position on the trajectory and it is exposed only to effects of a gravity force $G$. The effect of other forces is not taken into account as they all acted to the moment $t=0$, in which the particle gained initial speed $u_{o}$ which replaces their effect on particle.

If we project all forces in $x$ and $y$ axis, we get:

$m \frac{\mathrm{d}^{2} x}{\mathrm{~d} t^{2}}=m \ddot{x}=\sum X_{i}=-G \cdot \sin \alpha$

$m \frac{\mathrm{d}^{2} y}{\mathrm{~d} t^{2}}=m \ddot{y}=\sum Y_{i}=-G \cdot \cos \alpha$

For the initial conditions of movement $\left(t_{0}=0, x=0, y\right.$ $=0)$ it is accepted:

$\frac{\mathrm{d} x}{\mathrm{~d} t}=\dot{x}=u_{o} \cdot \cos \beta$

$\frac{\mathrm{d} y}{\mathrm{~d} t}=\dot{y}=u_{o} \cdot \sin \beta$

$u_{o}=\omega \cdot A \cdot \sin \omega t_{o}$

Integrating the system of Eqs. (6) by the time for the initial conditions (7), the parametric equations of motion of rejected earth particles are obtained:

$x=u_{o} \cdot \cos \beta \cdot t-\frac{g t^{2}}{2} \cdot \sin \alpha$

$y=u_{o} \cdot \sin \beta \cdot t-\frac{g t^{2}}{2} \cdot \cos \alpha$

The duration of the flight of rejected earth particle is identified from the Eq. ( $\left.8^{\prime}\right)$ by replacing $y=0$, because at that moment the particle has already fallen to the grid (point "P" in Fig. 5):

$t=\frac{2 \cdot u_{o} \cdot \sin \beta}{g \cdot \cos \alpha}$

To ensure continuity of platform operation in rejecting particles, the duration of the flight of rejected earth particles must be equal to the time during which platform performs one full rotation of the eccentric shaft:

$t_{\mathrm{I}}=\frac{2 \cdot u_{o} \cdot \sin \beta}{g \cdot \cos \alpha}=\frac{2 \pi}{\omega}$
For two full rotations of the eccentric shaft of platform, the duration of flight of rejected particles is:

$t_{\mathrm{II}}=\frac{2 \cdot u_{o} \cdot \sin \beta}{g \cdot \cos \alpha}=\frac{4 \pi}{\omega}$

For three full rotations of the eccentric shaft of platform, the duration of flight of rejected particles is:

$t_{\mathrm{III}}=\frac{2 \cdot u_{o} \cdot \sin \beta}{g \cdot \cos \alpha}=\frac{6 \pi}{\omega}, \ldots$, etc.

If Eq. (7') is considered as initial speed of rejected earth particle, by using several identical mathematical transformations of Eqs. (10), (10') and (10") the following expressions are obtained:

$$
\begin{aligned}
& \left(\omega^{2} \cdot A\right)_{\text {II }}=3,3 \frac{g \cdot \cos \alpha}{\sin \beta}, \\
& \left(\omega^{2} \cdot A\right)_{\text {II }}=6,36 \frac{g \cdot \cos \alpha}{\sin \beta}, \\
& \left(\omega^{2} \cdot A\right)_{\text {III }}=9,47 \frac{g \cdot \cos \alpha}{\sin \beta}, \ldots
\end{aligned}
$$

By analogy, for $n$ rotations of the eccentric shaft of platform the following expression is obtained:

$$
\left(\omega^{2} \cdot A\right)_{n}=N \frac{g \cdot \cos \alpha}{\sin \beta}
$$

By substituting Eq. (2) into Eq. (11) and by solving it for $n$, we obtain the critical $\mathrm{rpm}(n)$ which is required for moving to operating mode with rejection of material. At the same time, it is also the optimum rpm of platform $n_{\mathrm{opt}}$ during which its performance is maximum in terms of transporting the earth mass:

$[n]=n_{\mathrm{opt}}=30 \sqrt{\frac{N \cdot \cos \alpha}{A \cdot \sin \beta}}$

The coefficient $N$ in Eq. (12) has the following values:

$N=3,3 ; 6,36 ; 9,47 ; 12,6 ; 15,7 ; 18,9 ; \ldots ;$ etc.

On the basis of Eq. (12) we can conclude that the optimum rpm of vibrating transport platform depends on the following three geometrical values:

- $\quad$ amplitude of platform oscillation $(A)$

- angle of inclination of the platform grid in relation to horizontal $(\alpha)$

- $\quad$ angle of transport of platform $(\beta)$.

Therefore, it can be written that:

$$
n_{\mathrm{opt}}=f(A ; \alpha ; \beta)
$$

On the basis of Eq. (13) the following hypothesis of research can be formed: 
$\mathrm{H}$ : We introduce the assumption that all three above mentioned values: $A, \alpha, \beta$ are significant values which affect optimal performance of vibrating transport platform (optimal transportation of dry earth mass) by continual rejection of earth particles on the principle of the projectile motion. Accuracy of mentioned assumption will be verified after the experimental phase of the research, using a statistical method known as the dispersion analysis.

\section{Selection of factor levels of experimental factors and plan matrices for experiments}

The basic aim of experimental phase of the research is to form the appropriate mathematical model, based on the results of measurements, which adequately describes the work of platform in real operating conditions, i.e. the work of platform with the optimal operating modes having maximum efficiency in terms of earth mass transportation.

In order to create a mathematical model we used response surface methodology (RSM) which is described in the expert papers $[7 \div 10]$. This method includes the application of design of experiments (DoE), regression analysis and analysis of variance (ANOVA).

The application of response surface methodology (RSM) in various areas of engineering and in the field of agriculture is shown in the expert papers [11:15] and $[16 \div 18]$ respectively.

Optimization of influential parameters of the model by using response surface methodology (RSM) is shown in the expert papers $[12,15,18]$.

On the basis of Eq. (13) it is possible to set the following mathematical formulation:

$y=f\left(x_{1} ; x_{2} ; x_{3}\right)$

Eqs. (13) and (14) result in identical equalities:

$y \equiv n_{\mathrm{opt}} ; x_{1} \equiv A ; x_{2} \equiv \alpha ; x_{3} \equiv \beta$

Geometric parameters $A, \alpha, \beta$ have the character of input values, i.e. independent variables, while kinematic parameter $n_{\text {opt }}$ is a function of response which has the character of output value, i.e. dependent variable.

Schematic presentation of the functional dependence (14) is shown in Fig. 6.

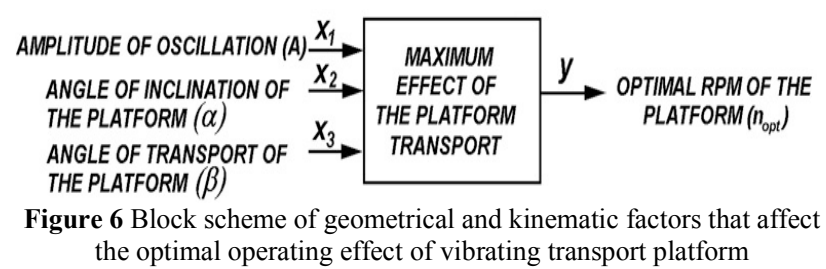

The selection of factor levels for all three influential factors is performed so that the upper (maximum) and the bottom (minimum) level are selected according to current recommendations from the literature, while the intermediate level is obtained as geometric mean value of the upper and lower levels. The recommended values of some factors according to [6] are:
$A_{\max }=25 \mathrm{~mm} ; A_{\min }=15 \mathrm{~mm}$;

$A_{\mathrm{sr}}=\sqrt{A_{\max } \cdot A_{\text {min }}}=\sqrt{25 \cdot 15}=19,4 \mathrm{~mm}$

We adopt: $A_{\text {sr }}=20 \mathrm{~mm}$;

$\alpha_{\max }=30^{\circ} ; \alpha_{\min }=10^{\circ}$;

$\alpha_{\mathrm{sr}}=\sqrt{\alpha_{\max } \cdot \alpha_{\min }}=\sqrt{30 \cdot 10}=17,3^{\circ}$

We adopt: $\alpha_{\mathrm{sr}}=20^{\circ}$;

$\beta_{\max }=25^{\circ} ; \beta_{\min }=15^{\circ}$;

$\beta_{\mathrm{sr}}=\sqrt{\beta_{\max } \cdot \beta_{\min }}=\sqrt{25 \cdot 15}=19,4^{\circ}$

We adopt: $\beta_{\text {sr }}=20^{\circ}$.

Selected factor levels are shown in Tab. 1.

Table 1 Factor levels - geometrical parameters of vibrating transport platform which vary in the course of the experiment

\begin{tabular}{|l|c|c|c|}
\hline \multicolumn{1}{|c|}{ Factors } & $\begin{array}{c}\text { Oscillation } \\
\text { amplitude } \\
A(\mathrm{~mm})\end{array}$ & $\begin{array}{c}\text { Angle of } \\
\text { inclination } \\
\alpha\left(^{\circ}\right)\end{array}$ & $\begin{array}{c}\text { Angle of } \\
\text { transport } \\
\beta\left(^{\circ}\right)\end{array}$ \\
\hline Maximum (upper) & 25 & 30 & 25 \\
\hline Intermediate (zero) & 20 & 20 & 20 \\
\hline Minimum (lower) & 15 & 10 & 15 \\
\hline
\end{tabular}

The factors from Tab. 1 vary in the course of the experiment in the range of its minimum value to a maximum prescribed value: $\left(A_{\min } \div A_{\max }\right),\left(\alpha_{\min } \div \alpha_{\max }\right)$, $\left(\beta_{\min } \div \beta_{\max }\right)$, in order to determine their influence on $n_{\text {opt }}$. Other factors that also affect the productivity of platform, which are not specified in Fig. 6 because they are not geometric in nature (humidity of earth, air resistance, supply of earth on the platform per unit of time, etc.), are maintained at a constant level, i.e. they do not vary in the course of the experiment, since they are not subject of research in this case.

Table 2 Plan-matrix for three-factor orthogonal plan of experiments type $2^{3}$

\begin{tabular}{|c|c|c|c|c|c|c|c|}
\hline \multirow{2}{*}{$\begin{array}{l}\text { Exp. } \\
\text { point }\end{array}$} & \multirow{2}{*}{$\begin{array}{l}\text { Oscillation } \\
\text { amplitude } \\
A(\mathrm{~mm})\end{array}$} & \multirow{2}{*}{$\begin{array}{c}\text { Angle of } \\
\text { inclination } \\
\alpha\left(^{\circ}\right)\end{array}$} & \multirow{2}{*}{$\begin{array}{c}\text { Angle of } \\
\text { transport } \\
\beta\left(^{\mathrm{o}}\right)\end{array}$} & \multicolumn{4}{|c|}{ Plan-matrix* } \\
\hline & & & & $x_{0}$ & $x_{1}$ & $x_{2}$ & $x_{3}$ \\
\hline 1 & 25 & 30 & 25 & 1 & 1 & 1 & 1 \\
\hline 2 & 15 & 30 & 25 & 1 & -1 & 1 & 1 \\
\hline 3 & 25 & 10 & 25 & 1 & 1 & -1 & 1 \\
\hline 4 & 15 & 10 & 25 & 1 & -1 & -1 & 1 \\
\hline 5 & 25 & 30 & 15 & 1 & 1 & 1 & -1 \\
\hline 6 & 15 & 30 & 15 & 1 & -1 & 1 & -1 \\
\hline 7 & 25 & 10 & 15 & 1 & 1 & -1 & -1 \\
\hline 8 & 15 & 10 & 15 & 1 & -1 & -1 & -1 \\
\hline 9 & 20 & 20 & 20 & 1 & 0 & 0 & 0 \\
\hline 10 & 20 & 20 & 20 & 1 & 0 & 0 & 0 \\
\hline 11 & 20 & 20 & 20 & 1 & 0 & 0 & 0 \\
\hline 12 & 20 & 20 & 20 & 1 & 0 & 0 & 0 \\
\hline
\end{tabular}

* In order to simplify when entering the experimental data in the planmatrix, maximum (upper) level is marked with +1 , minimum (lower) level with -1 , and intermediate (zero) level with 0 .

To perform the experiments multifactor orthogonal plan type $2^{k}$ was selected without taking into account the interactions of factors $(A, \alpha, \beta)$, with one measurement at each point of plan and with repetition of measurements at the zero point of the plan four times. 
Basic data related to the multifactor orthogonal plan of experimenting are: $k=3$ - number of influential factors in the experiment $(A, \alpha, \beta) ; n_{0}=4$ - number of repetitions of the measurements at the zero point of the plan; $N_{\mathrm{e}}=2^{k}$ $+n_{0}=2^{3}+4=12$ - total number of experiments.

The plan mentioned above with the order for performing of experiments is shown in Tab. 2 .

The full proceedings of experimenting and analysis of obtained results, is carried out according to the methodology which is in the form of the algorithm shown in Fig. 7.

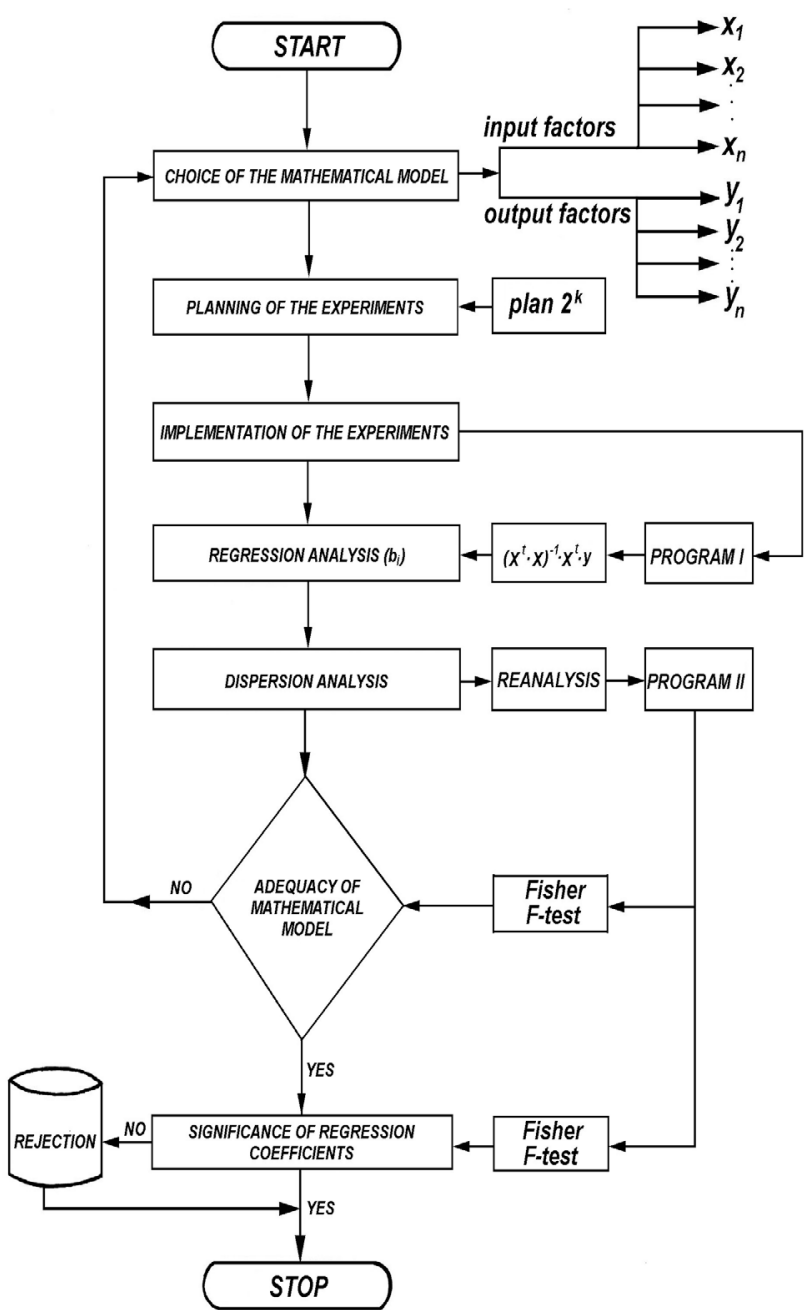

Figure 7 The methodology for realization of experiments

\section{The measurement results of the optimal rpm of oscillatory transport platform}

Complete experimental phase of the research was carried out in the laboratory in Guča (Serbia), on an experimental platform which is a prototype of an agricultural machine for the extraction of potatoes. For measuring the optimum rpm, a standard measuring and regulation equipment was used to create the ideal conditions for transport and fragmentation of earth mass (supply of dry and friable earth in the form of layered sediments without solid lumps to the platform).

The rpm $n_{\mathrm{opt}}$ is considered to be the number of rotations of eccentric shaft of the platform where the duration of the flight of rejected earth particles is maximum, because the distance of rejected particles is the longest during that period (maximum transport of earth mass). Measured values of the $\mathrm{rpm} n_{\mathrm{opt}}$ for all 12 experimental points are given in Tab. 3 .

Table 3 Measured values $n_{\mathrm{opt}}$ in the course of experiments

\begin{tabular}{|c|c|c|c|c|c|c|c|c|c|c|c|c|}
\hline $\begin{array}{c}\text { Experim. } \\
\text { points }\end{array}$ & 1 & 2 & 3 & 4 & 5 & 6 & 7 & 8 & 9 & 10 & 11 & 12 \\
\hline$n_{\text {opt }}\left(\mathrm{min}^{-1}\right)$ & 530 & 700 & 590 & 730 & 710 & 880 & 710 & 950 & 700 & 690 & 690 & 710 \\
\hline$y_{i}=\ln \left(n_{\text {opt }}\right)$ & 6,27 & 6,55 & 6,38 & 6,59 & 6,57 & 6,78 & 6,57 & 6,86 & 6,55 & 6,54 & 6,54 & 6,57 \\
\hline
\end{tabular}

\section{Mathematical model in coded and decoded form}

The general mathematical model with no mutual influence of factors $x_{1}, x_{2}, x_{3}$ has the following form:

$y=b_{0} \cdot x_{0}+b_{1} \cdot x_{1}+b_{2} \cdot x_{2}+b_{3} \cdot x_{3}$

where: $y$ - logarithmic value of the measured values; $b_{0}$, $b_{1}, \quad b_{2}, \quad b_{3}-$ regression coefficients which are calculated by regression analysis, which have the following values (Tab. 3):

$b_{0}=6,56417 ; b_{1}=-0,12375 ; b_{2}=-0,02875$;

$b_{3}=-0,12375$

By substituting the coefficients from Eq. (17) into Eq. (16) and keeping in mind that the value $x_{0}=1$ according to Tab. 2, the mathematical model has the coded form as follows:

$y=6,56417-0,12375 x_{1}-0,02875 x_{2}-0,12375 x_{3}$

Mathematical model in decoded form has the following form:

$$
y=14544,96 \cdot x_{1}^{-0,484} \cdot x_{2}^{-0,052} \cdot x_{3}^{-0,484}
$$

By substituting the identical equalities from Eq. (15) into Eq. (19) we obtain the final form of the required mathematical model:

$$
\begin{aligned}
& n_{\mathrm{opt}}=14544,96 \cdot A^{-0,484} \cdot \alpha^{-0,052} \cdot \beta^{-0,484} \\
& n_{\mathrm{opt}}=\frac{14544,96}{A^{0,484} \cdot \alpha^{0,052} \cdot \beta^{0,484}}
\end{aligned}
$$

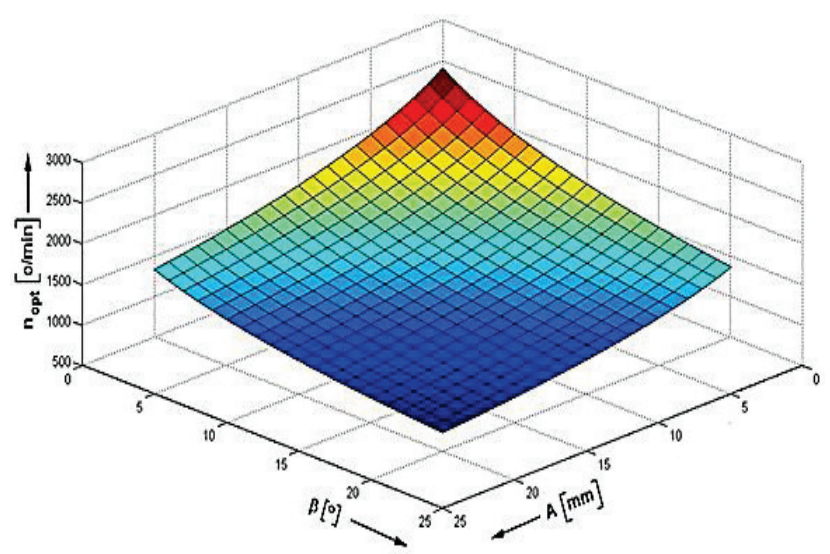

Figure 8 Optimization of geometrical operating parameters that affect the work of vibrating transporting platform during transportation of dry earth mass 
Considering that $\alpha=$ const. (because the factor $\alpha$ is the least influential of all three relevant factors), graphical presentation of the optimization of geometrical operating parameters which, according to Eq. (20), influence the work of vibrating platform during transportation of dry earth mass is shown in Fig. 8.

\section{Graphical interpretation of research results}

Fig. 9 shows the correlation of the input-output parameters, i.e. it gives a graphical presentation of dependency of optimal rpm of vibrating transport platform $n_{\text {opt }}$ on geometrical parameters of the platform: $A, \alpha, \beta$. The upper and the lower theoretical curves in all diagrams are graphical interpretation of Eq. (12), while experimentally obtained intermediate curve is graphical interpretation of Eq. (20). The diagram also shows that interdependence of input and output parameters is nonlinear, i.e. it is presented through a series of curves being hyperbolic type.
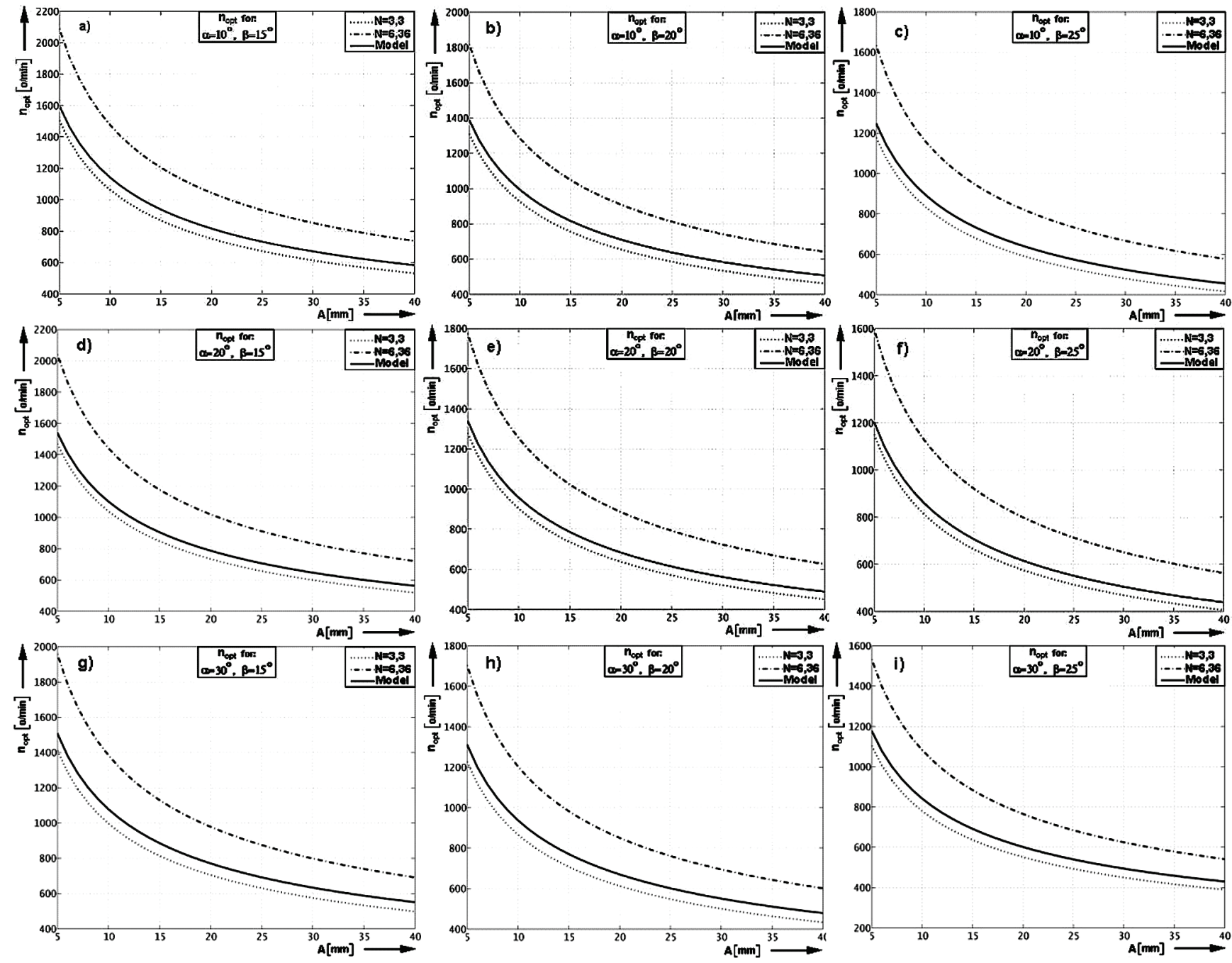

Figure 9 Graphical presentation of the results of theoretical and experimental research

\section{Result discussions}

Theoretical analysis of transport of dry earth mass using the machine with built-in vibrating platforms is based on the elementary assumptions and principles presented in expert paper [19], which are also presented within the items 2, 3 and 4 of this paper. The following parameters are influential on the work efficiency of vibrating platforms for transport of dry earth mass:

- Geometrical parameters (Fig 2) which depend on structural solutions applied to each particular machine with built-in platform. By varying these parameters it is possible to achieve different operating effects that primarily depend on the purpose (application areas) of the platform machine.
- Kinematic parameters (Fig. 4) indicate that the operating part of platform performs a typical oscillatory movement, where the speed and the acceleration of platform grid are defined by Eqs. (4) and (5). This movement causes an inertial force $F^{\text {in }}$ which is always directed opposite of the acceleration of grid, which allows the transport of particles of earth mass along the platform grid. Kinematic analysis of oscillatory motion of the platform was made for all five possible operating modes (diagrams in Fig. 4), where it is determined that the optimal operating mode is the mode during which the material is rejected from the platform by the principle of projectile motion (the case "e" in Fig. 4).

- Using the experimental vibrating platform [19], the practical verification of the hypothesis $\mathrm{H}$ was performed 
and an assumption that the $n_{\mathrm{opt}}=f(A ; \alpha ; \beta)$ was introduced. After conducting the experiments, which were performed according to composed plan-matrix (Tab. 2), the following concrete conclusions are derived:

All three previously varied geometrical values $(A ; \alpha$; $\beta$ ) are statistically significant values which considerably affect the optimal rpm of platform which directly influences the performance of vibrating transport platform. The mathematical model given by Eq. (20) shows the aforementioned dependence, because it has been proven, using dispersion analysis, that this model adequately describes the analyzed transportation process. The hypothesis $\mathrm{H}$ is completely accepted.

Through Eq. (20) it is obvious that the increase of values $A, \alpha, \beta$, makes the measured value $n_{\text {opt }}$ decrease, which shows that there is a reverse proportionality between these factors. Therefore in the exp. point 1 the lowest value for $n_{\text {opt }}$ was obtained (530 $\mathrm{min}^{-1}$ according to Tab. 3), because in this case the values of all three varied factors are maximal $\left(A_{\max }=25 \mathrm{~mm}, \alpha_{\max }=30^{\circ}, \beta_{\max }=25^{\circ}\right.$ according to Tab. 2). On the other hand, the highest value for $n_{\mathrm{opt}}$ was obtained in the exp. point $8\left(950 \mathrm{~min}^{-1}\right.$ according to Tab. 3), because the values of all three varied factors are minimal $\left(A_{\min }=15 \mathrm{~mm}, \alpha_{\min }=10^{\circ}, \beta_{\min }=15^{\circ}\right.$, Tab. 2).

Eqs. (19) and (20) show that $\varphi_{1}=\varphi_{3}=-0,484$ and $\varphi_{2}$ $=-0,052$, so it is obvious that $\left|\varphi_{1}\right|>\left|\varphi_{2}\right|$, and $\left|\varphi_{3}\right|>$ $\left|\varphi_{2}\right|$, which means that the rpm of platform is under a much greater influence of amplitude of oscillation $A$ and angle of transport of platform $\beta$, while the angle of inclination of platform towards the horizontal $\alpha$ has considerably less influence.

- Diagrams (Fig. 9) demonstrate full correlation between the theoretical and experimental research results. The curve obtained on the basis of experimental mathematical model given by Eq. (20) is always between the curves obtained from the theoretical model given by Eq. (12), where all three characteristic curves on diagrams are of hyperbolic type.

- A typical coefficient $N=3,3$ in the diagrams refers to low-speed operating mode, while coefficient $N=6,36$ refers to high-speed operating mode of vibrating transport platform. All experiments were performed at low-speed operating mode. Diagrams show that the actual optimal rpm of platform are slightly larger than the theoretical optimal rpm, because the actual rpm curve is always above the theoretical rpm curve. This is due to air resistance which opposes the movement of rejected earth particles during projectile motion which is not taken into consideration in experimentally derived mathematical model presented by Eq. (20). However, the difference in the optimum rpm is very small, so it can be completely neglected in practical situations.

\section{Conclusions}

Optimisation of parameters influencing the operation of machinery and equipment which use vibrating platforms for transporting and sieving of dry earth mass is a very complex and complicated problem. For this purpose it is necessary to carry out numerous theoretical and experimental researches which must be based on results published in scientific and professional community.

The contribution of research conducted in this paper is reflected in the scientific verification of two very important facts:

- With the increase of amplitudes of platform oscillation within the range of 5 to $15 \mathrm{~mm}$, the frequencies of oscillations necessary for optimal operating mode with material rejection are sharply reduced (Fig. 9). By increasing the amplitudes within the range of 15 to 30 $\mathrm{mm}$, the mentioned frequencies of oscillations are slightly reduced. Further increase of oscillation amplitudes practically has no effect, and therefore the operation of vibrating platforms with amplitudes greater than $30 \mathrm{~mm}$ is quite irrational and inadvisable [19].

- Required acceleration of platform is more appropriate to achieve by increasing frequencies of oscillations instead of increasing the amplitudes of oscillations [19].

Results and conclusions obtained in the paper are of particular interest for modification of the existing machines and devices, and for producing completely new ones, too. At the end of this paper the concrete proposals and recommendations are specified for the purpose of further research in this field.

During the experimental phase of the research, the platform performed harmonic motion wherein the speed and the acceleration of platform changed in conformity with the law of sinus (or cosine) according to Eqs. (4) and (5).

Further research should be directed towards nonharmonic movement of the platform in order to increase its transportation capacity. The greatest problems in the operation of machines and devices with vibration platforms occur after heavy rains, i.e. when earth moisture becomes extremely large. Then the effect of transport and separation is the weakest, due to sticking of wet earth on the platform grid. In addition, further research should be directed to finding answers to the question how vibrating platform would operate in extremely difficult working conditions with a maximum moist and plastic earth (so called "heavy loam").

\section{References}

[1] Beenken, W.; Gock, E.; Kurrer, K. E. The outer mechanics of the eccentric vibration mill. // International Journal of Mineral Processing. 44-45, (1996), pp. 437-446.

[2] Dewangan, K. N.; Tewari, V. K. Characteristics of handtransmitted vibration of a hand tractor used in three operational modes. // International Journal of Industrial Ergonomics. 39, 1(2009), pp. 239-245. DOI: 10.1016/j.ergon.2008.08.007

[3] Krolczyk, G. M.; Krolczyk, J. B.; Legutko, S.; Hunjet, A. Effect of the disc processing technology of the vibration level of the chipper during operations. // Tehnički vjesnik. 21, 2(2014), pp. 447-450.

[4] Klanfar, M.; Kujundžić, T.; Vrkljan, D. Calculation analysis of bulldozer's productivity in gravitational transport on open pits. // Tehnički vjesnik. 21, 3(2014), pp. 517-523.

[5] Suprem, A.; Mahalik N.; Kim, K. A. Review on application of technology systems, standards and interfaces for agriculture and food sector. // Computer Standards \& Interfaces. $35, \quad 4(2013), \quad$ pp. 355-364. DOI: 10.1016/j.csi.2012.09.002 
[6] Korpenko, N. A. Selyskohozyastveniye mashini, Kolos, Moskva, Russia, 1973.

[7] Barrentine, L. B. An introduction to design of experiments: A simplified approach. American Society for Quality (ASQ) Press, Milwaukee, Wisconsin, USA, 1999.

[8] Box, G. E. P.; Wilson, K. B. On the experimental attainment of optimum conditions. // Journal of the Royal Statistical Society: Series B (Methodological). 13, 1(1951), pp. 1-45.

[9] Montgomery, D. C. Design and analysis of experiments. $8^{\text {th }}$ Edition, John Wiley \& Sons Inc., Hoboken, New Jersey, USA, 2012.

[10] Myers, R. H.; Montgomery, D. C.; Vining, G. G.; Borror, C. M.; Kowalski, S. M. Response surface methodology: A retrospective and literature review. // Journal of Quality Technology. 36, 1(2004), pp. 53-77.

[11] Amado, I. R.; Franco, D.; Sánchez, M.; Zapata, C.; Vázquez, J. A. Optimisation of antioxidant extraction from Solanum tuberosum potato peel waste by surface response methodology. // Food Chemistry. 165, (2014), pp. 290-299. DOI: 10.1016/j.foodchem.2014.05.103

[12] Chomsamutr, K.; Jongprasithporn, S. Optimization parameters of tool life model using the Taguchi approach and response surface methodology. // International Journal of Computer Science Issues (IJCSI). 9, 3(2012), pp. 120125.

[13] Dašić, P. Comparative analysis of different regression models of the surface roughness in finishing turning of hardened steel with mixed ceramic cutting tools. // Journal of Research and Development in Mechanical Industry. 5, 2(2013), pp. 101-180.

[14] Ibrahim H. M.; Elkhidir, E. E. Response surface method as an efficient tool for medium optimisation. // Trends in Applied Sciences Research. 6, 2(2011), pp. 121-129. DOI: 10.3923/tasr.2011.121.129

[15] Subramanian, M.; Sakthivel, M.; Sooryaprakash, K.; Sudhakaran, R. Optimization of end mill tool geometry parameters for A17075-T6 machining operations based on vibration amplitude by response surface methodology. // Measurement. 46, 10(2013), pp. 4005-4022. DOI: 10.1016/j.measurement.2013.08.015

[16] Dalvand, M. J.; Mohtasebi, S. S.; Rafiee, S. Modeling of electrohydrodynamic drying process using response surface methodology. // Food Science \& Nutrition. 2, 3(2014), pp. 200-209. DOI: $10.1002 / \mathrm{fsn} 3.96$

[17] Edmondson, R. N. Agricultural response surface experiments based on four-level factorial designs. // Biometrics. 47, 4(1991), pp. 1435-1448. DOI: $10.2307 / 2532397$

[18] Madamba, P. S. The response surface methodology: An application to optimize dehydration operations of selected agricultural crops. // LWT - Food Science and Technology. 35, 7(2002), pp. 584-592. DOI: 10.1016/S0023-6438(02)90914$\mathrm{X}$

[19] Mihajlović, G. Modelling and dynamical analysis of the process of dry land mass transport by means of vibrating oscillatory platform. // IMK-14-Research and Development in Heavy Machinery. 19, 1(2013), pp. EN1-EN6.

\section{Authors' addresses}

Goran Mihajlović, MSc, Professor of applied studies Higher Technical School of Mechanical Engineering Radoja Krstića 19, 37240 Trstenik, Serbia E-mail: goran.vtms@gmail.com

\section{Milomir Gašić, PhD, Full professor}

Faculty of Mechanical and Civil Engineering Dositejeva 19, 36000 Kraljevo, Serbia

E-mail: gasic.m@mfkv.kg.ac.rs

Mile Savković, PhD, Full professor

Faculty of Mechanical and Civil Engineering Dositejeva 19, 36000 Kraljevo, Serbia

E-mail: savkovic.m@mfkv.kg.ac.rs 